\title{
PENGARUH PERSEPSI HARGA, KUALITAS PRODUK, DAN KEPUASAN PELANGGAN TERHADAP MINAT PEMBELIAN ULANG
}

\author{
Yudi Darma \\ Progran Studi Magister Manajemen Universitas Tarumanagara \\ yudi_dharma@ymail.com
}

Masuk : 06-12-2019, revisi : 21-12-2019 diterima untuk diterbitkan : 23-12-2019

\begin{abstract}
This research was aiming to determine the effect of price perception, product quality and customer satisfaction on repurchase intention. The sampling technique used in this study is nonprobability sampling by convenience sampling. Sampling using a quantitative approach by distributing questionnaires to 126 respondents in Jakarta. For operational variables using the Likert scale. The data analysis method uses regression data analysis which is processed through the SPSS program. Based on the results of this study indicate that significant positive price perceptions, positive significant product quality, significant positive customer satisfaction on repurchase intention. In this research, price perception has the most influence on repurchase intention.
\end{abstract}

Keywords : Price Perception; Product Quality; Customer Satisfaction; Repurchase Intention

Abstract : Penelitian ini bertujuan untuk mengetahui pengaruh persepsi harga, kualitas produk, dan kepuasan pelanggan terhadap minat pembelian ulang. Teknik pengambilan sampel yang digunakan dalam penelitian ini adalah nonprobability sampling dengan convenience sampling. Sampel menggunakan pendekatan kuantitatif dengan mendistribusikan kuesioner kepada 126 responden di Jakarta. Untuk variabel operasional menggunakan skala Likert. Metode analisis data menggunakan analisis data regresi yang diproses melalui program SPSS. Berdasarkan hasil penelitian ini menunjukkan bahwa persepsi harga positif signifikan, kualitas produk signifikan positif, kepuasan pelanggan positif signifikan terhadap niat pembelian kembali. Dalam penelitian ini, persepsi harga memiliki pengaruh paling besar terhadap niat pembelian kembali.

Kata Kunci : Persepsi Harga; Kualitas Produk; Kepuasan Pelanggan; Minat Pembelian Ulang

\section{PENDAHULUAN}

Kebutuhan akan fashion di jaman modern seperti sekarang ini semakin tinggi, dengan semakin tingginya kebutuhan tentu perusahaan - perusahaan akan semakin bersaing untuk memasarkan produknya dan melebarkan pasarnya agar semakin dikenal. Persaingan yang semakin ketat antara perusahaan membuat setiap perusahaan perlu untuk meningkatkan minat pembelian ulang dari pelanggannya agar produk yang dijual pun diharapkan semakin meningkat, sehingga setiap perusahaan dirasa perlu meneliti factor-faktor yang dapat meningkatkan minat pembelian ulang dari seorang konsumen. Menurut Joseph, et al. (2012) minat pembelian ulang dapat di pengaruhi oleh factor persepsi harga dan kepuasan pelanggan. Persepsi harga sebagai pandangan dari konsumen terhadap suatu produk apakah layak atau tidak untuk di konsumsi dan sepadan dengan apa yang dikeluarkan untuk barang tersebut.

Awi dan Chaipoopirutana (2014) menjelaskan bahwa minat pembelian ulang dapat di pengaruhi oleh factor kualitas produk. Kualitas produk yang dirasa baik dari seorang konsumen akan membuat konsumen tersebut tidak ragu untuk mengkonsumsi ulang produk tersebut. Pupuani dan Sulistyawati (2013) menjelaskan bahwa minat pembelian ulang dapat dipengaruhi oleh factor kepuasan pelanggan. Konsumen yang telah merasa puas dengan suatu produk tentu 
akan berdampak baik bagi perusahaan, karena produk tersebut akan menjadi prioritas dari konsumen tersebut dan akan dikonsumsi secara berulang. Konsumen pun tidak akan ragu untuk membeli produk lain yang dihasilkan perusahaan karena telah memiliki kepuasan tersendiri saat mengkonsumsi produk dari perusahaan. Hasil dari penelitian ini diharapkan agar perusahaan selalu memperhatikan faktor persepsi harga, kualitas produk dan kepuasan pelanggan dalam setiap kegiatan operasional perusahaan. Hal itu karena ketiga faktor tersebut sudah terbukti sangat berpotensi dalam meningkatkan minat pembelian ulang.

\section{TELAAH KEPUSTAKAAN \\ Persepsi Harga}

Masoom (2014:105) mendefinisikan persepsi harga yaitu "Price perception is the amount of sacrifice expressed in the amount of money for goods or services to be obtained". Persepsi harga dapat dipersepsikan mengenai pandangan dari konsumen terhadap harga sebuah produk layak atau tidak untuk dikonsumsi. Menurut Hariyanti (2011) menyatakan bahwa persepsi harga memiliki hubungan yang positif dengan minat pembelian ulang.

\section{Kualitas Produk}

Menurut Haffman dan Rateson (2011:4) "Product Quality is a standard of correspondence between the actual performance of the service with the customers' expectations or the difference between the customers' expectations and their realization of the service's actual performance". Lebih lanjut menurut Chowdury (2017) menyatakan bahwa kualiats produk memiliki hubungan positif terhadap minat pembelian ulang. Mengenai kualitas produk, penulis berpendapat bahwa semakin baik kualitas dari sebuah produk akan menjadi pilihan utama bagi seorang konsumen.

\section{Kepuasan Pelanggan}

Menurut Kotler dan Keller (2012:156) mengemukakan "Consumer satisfaction is a feeling of pleasure or disappointment someone after comparing the performance of a product with their expectations". Selanjutnya Huang, et. Al (2014) turut mengemukakan bahwa kepuasan pelanggan memiliki hubungan positif terhadap minat pembelian ulang. Kepuasan pelanggan merupakan hasil dari apa yang dirasakan konsumen setelah mengkonsumsi suatu produk.

\section{Minat Pembelian Ulang}

Menurut Hellier et al. (2003:1765) mengemukakan minat pembelian ulang sebagai "The individual's judgement about buying again a designated service from the same company. Taking into account his or her current situation and likely circumtance". Minat pembelian ulang akan dilakukan apabila harapan dari seorang konsumen terhadap sebuah produk telah terpenuhi.

\section{Kaitan Antar Variabel \\ Pengaruh Persepsi Harga terhadap Minat Pembelian Ulang}

Menurut Penelitian yang dilakukan oleh Supriono (2017) menyatakan bahwa persepsi harga memiliki hubungan yang positif dengan minat pembelian ulang. Persepsi yang dapat diterima baik oleh konsumen membuat konsumen tidak ragu untuk membeli kembali. Lebih lanjut menurut Hariyanti (2011) menyatakan bahwa persepsi harga memiliki hubungan yang positif dengan minat pembelian ulang. Harga yang sebanding dengan apa yang didapatkan tentu membuat konsumen tidak ragu untuk mengkonsumi produk tersebut, konsumen lebih memilih produk dengan harga yang bersaing namun mampu memenuhi harapan dari konsumen tentang sebuah produk. Dalam penelitian yang dilakukan Rohwiyati \& Praptriestrini (2019) 
mengemukakan bahwa persepsi harga memiliki hubungan positif terhadap minat pembelian ulang. Berdasarkan pernyataan diatas, maka hipotesis penelitian ini adalah sebagai berikut :

H1 : Terdapat pengaruh positif persepsi harga terhadap minat pembelian ulang.

\section{Pengaruh Kualitas Produk terhadap Minat Pembelian Ulang}

Menurut Ketut (2018) mengemukakan bahwa kualitas produk memiliki hubungan positif terhadap minat pembelian ulang. Lebih lanjut Chowdury (2017) menyatakan bahwa kualiats produk memiliki hubungan positif terhadap minat pembelian ulang. Konsumen akan lebih memilih menggunakan produk dengan kualitas yang baik agar dapat memenuhi harapan dari konsumen tersebut. Selanjutnya menurut Aryadhe dan Rastini (2016) turut mengemukakan bahwa kualitas produk memiliki hubungan positif terhadap minat pembelian ulang. Produk yang memiliki kualitas yang baik akan membuat produk tersebut terus dipakai oleh konsumen. Berdasarkan pernyataan diatas, maka hipotesis penelitian ini adalah sebagai berikut :

$\mathrm{H} 2$ : Terdapat pengaruh positif kualitas produk terhadap minat pembelian ulang.

\section{Pengaruh Kepuasan Pelanggan terhadap Minat Pembelian Ulang.}

Menurut Chamchuntra dan fongsuwan (2014) mengemukakan bahwa kepuasan pelanggan memiliki hubungan positif terhadap minat pembelian ulang. Konsumen yang merasa puas dengan sebuah produk tentu akan membuat produk tersebut terus dikonsumsi. Hal tersebut sejalan dengan penelitian yang dilakukan oleh Hume dan Mort (2010) yang mengemukakan bahwa kepuasan pelanggan memiliki hubungan positif terhadap minat pembelian ulang. Konsumen yang telah merasa terpenuhi harapannya akan sebuah produk, membuat konsumen tersebut tidak akan ragu dalam melakukan pembelian ulang. Selanjutnya Huang, et. Al (2014) turut mengemukakan bahwa kepuasan pelanggan memiliki hubungan positif terhadap minat pembelian ulang. Berdasarkan pernyataan diatas, maka hipotesis penelitian ini adalah sebagai berikut :

H3 : Terdapat pengaruh positif kepuasan pelanggan terhadap minat pembelian ulang.

Model Penelitian

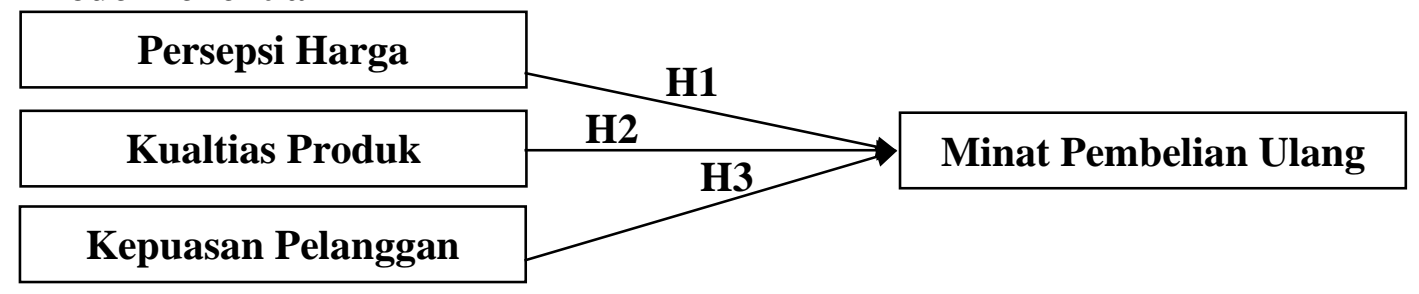

\section{METODOLOGI PENELITIAN}

Penelitian ini merupakan penelitian deskriptif. Dalam penelitian ini yang menjadi populasi adalah seluruh pelanggan yang pernah membeli maupun mengetahui produk dari perusahaan. Untuk teknik pengambilan sampel, dalam penelitian ini menggunakan convenience sampling. Responden yang terkumpul dan memenuhi kriteria yaitu sebanyak 126 responden. Setelah setiap data pernyataan yang terkumpul valid untuk digunakan, selanjutnya data tersebut dianalisis mulai dari subjek penelitian yaitu mayoritas responden perempuan berusia 21-30 tahun, memiliki pekerjaan sebagai pegawai swasta atau negeri, memiliki pendapatan 2.000.000 - 9.900.000, dan alasan memilih produk perusahaan dibanding produk lain karena nyaman dengan merek dari perusahaan.

Pada penelitian ini, variabel persepsi harga, kualitas produk dan kepuasan pelanggan merupakan variabel independent. Sedangkan minat pembelian ulang merupakan variabel dependent. Skala Likert yang digunakan dalam penelitian ini menggunakan skala 5 poin dengan 1 menunjukkan "sangat tidak setuju" dan 5 menunjukkan "sangat setuju" 
Metode analisis data yang digunakan yaitu analisis regresi berganda. Sedangkan untuk uji asumsi klasik seperti uji multi kolinearitas, uji normalitas dan uji heterokedastisitas telah dilakukan sebelumnya dengan hasil yang menunjukkan bahwa semua uji asumsi sudah terpenuhi. Semua pengujian dalam penelitian ini menggunakan SPSS dengan taraf signifikan yang berlaku dalam penelitian ini adalah 0,05 .

Tabel dibawah ini menujukkan pengukuran dari masing-masing variabel beserta sumbernya.

Tabel 1

Variabel dan Pengukuran

\begin{tabular}{|l|c|l|}
\hline \multicolumn{1}{|c|}{ Variabel } & Item & \multicolumn{1}{c|}{ Sumber } \\
\hline Persepsi Harga (X1) & 4 & Hariyanti (2011) \\
\hline Kualitas Produk (X2) & 5 & Dewi, Magdalena, dan Dhiana (2014) \\
\hline Kepuasan Pelanggan (X3) & 6 & Huang, et al. (2014) \\
\hline Minat Pembelian Ulang (Y) & 4 & Huang, et al. (2014) \\
\hline
\end{tabular}

\section{ANALISA DAN PEMBAHASAN}

\section{Tabel 2}

\section{Hasil Pengujian Hipotesis}

\begin{tabular}{|ll|c|c|c|}
\hline \multicolumn{1}{|c|}{ Hipotesis } & B & Sig & Kesimpulan \\
\hline H1 & $\begin{array}{l}\text { Terdapat pengaruh positif antara persepsi harga terhadap minat } \\
\text { pembelian ulang }\end{array}$ & 0,424 & 0,000 & $\begin{array}{c}\text { Tidak } \\
\text { Ditolak }\end{array}$ \\
\cline { 2 - 4 } H2 & $\begin{array}{l}\text { Terdapat pengaruh positif antara kualitas produk terhadap } \\
\text { minat pembelian ulang }\end{array}$ & 0,387 & 0,000 & $\begin{array}{c}\text { Tidak } \\
\text { Ditolak }\end{array}$ \\
\cline { 2 - 4 } H3 & $\begin{array}{l}\text { Terdapat pengaruh positif antara kepuasan pelanggan terhadap } \\
\text { minat pembelian ulang }\end{array}$ & 0,170 & 0,004 & $\begin{array}{c}\text { Tidak } \\
\text { Ditolak }\end{array}$ \\
\hline
\end{tabular}

Berdasarkan hasil dari pengujian hipotesis diatas, maka dapat disimpulkan bahwa persepsi harga, kualitas produk dan kepuasan pelanggan berpengaruh positif terhadap minat pembelian ulang. Mengenai hal ini, dapat diartikan bahwa tingkat pembelian yang tinggi dari konsumen terhadap produk Zara karena faktor persepsi harga yang sesuai, kualitas produk dan kepuasan pelanggan yang mendapat respon baik dari konsumen. Hipotesis $\mathrm{H} 1$ tersebut sesuai dengan yang diteliti oleh Joseph, et al. (2012) mengungkapkan bahwa persepsi harga berpengaruh signifikan terhadap minat pembelian ulang. Ketika konsumen merasa cocok dengan persepsi harga yang ada makan konsumen tidak akan ragu untuk mengkonsumsi produk tersebut, konsumen akan kecewa apabila persepsi harga yang dirasakan tidak sesuai dengan produk yang didapat. Penulis dapat menyimpulkan bahwa persepsi harga yang seusai akan membangun minat pembelian ulang terhadap sebuah produk. Selanjutnya H2 sesuai dengan yang diteliti oleh Chowdury (2017) yang mengungkap bahwa kualitas produk memiliki pengaruh signifikan terhadap minat pembelian ulang. Kualitas produk yang baik yang dihasilkan oleh perusahaan akan berdampak bagi minat dari konsumen untuk lebih mengkonsumsi produk tersebut yang akan memberikan dampak positif bagi penjualan. Kemudian H3 sesuai dengan yang diteliti oleh Chamchuntra dan fongsuwan (2014) mengemukakan bahwa kepuasan pelanggan berpengaruh signifikan terhadap minat pembelian ulang. Konsumen memiliki tingkat kepuasan yang tinggi terhadap sebuah produk, tentu konsumen tersebut tidak akan ragu untuk mengkonsumsi ulang produk tersebut secara berkala, karena konsumen tersebut merasa harapannya akan sebuah produk telah terpenuhi dan yakin bahwa apa yang dikeluarkan untuk produk tersebut sebanding dengan apa yang akan didapatkan dari produk tersebut.

Dengan demikian maka seluruh hipotesis dalam penelitian ini dapat dibuktikan dengan data secara empiris. Minat pembelian ulang dapat diprediksi oleh persepsi harga, kualitas 
produk dan kepuasan pelanggan. Maka dapat dilihat bahwa minat pembelian ulang dipengaruhi oleh persepsi harga yang sesuai, kualitas produk yang sepadan dan kepuasan pelanggan yang tinggi yang dirasakan oleh konsumen terhadap produk dari Zara.

\section{PENUTUP \\ Kesimpulan}

Setiap pelaku bisnis, selalu mengharapkan yang terbaik bagi bisnis yang dijalankan tersebut. Keberlangsungan suatu bisnis tidak bisa lepas dari minat pembelian ulang seorang konsumen. Tidak hanya mengandalkan nama besar dari bisnisnya tersebut, namun masih ada faktor lain seperti persepsi harga, kualitas produk dan kepuasan pelanggan yang dapat membuat sebuah bisnis dapat berjalan dan bertahan lama. Persepsi harga yang tepat dalam pandangan konsumen membuat konsumen tidak ragu untuk mengkonsumsi produk tersebut. Demikian dengan kualitas produk, konsumen tentu akan lebih memilih menggunakan produk dengan kualitas yang baik yang mampu memberikan fungsi yang maksimal pula karena lebih dapat diandalkan. Begitu pula dengan kepuasan pelanggan, semakin tinggi tingkat kepuasan yang dirasakan seorang pelanggan ketika mengkonsumsi sebuah produk, maka akan semakin tinggi pula minat pembelian ulang produk tersebut, hal ini karena konsumen merasa tepat dalam memilih produk tersebut dan tidak ada alasan bahwa tidak menggunakan produk tersebut.

\section{Saran}

Berdasarkan penelitian ini, peneliti dapat menyarankan agar perusahaan dapat lebih memperhatikan faktor persepsi harga, kualitas produk dan kepuasan pelanggan dalam kegiatan operasionalisasi. Hal ini didasarkan pada penelitian diatas yang menyatakan bahwa ketiga variabel tersebut sangat teridentifikasi dan berpotensi dalam menciptakan minat pembelian ulang. Peneliti juga menyarankan perusahaan agar terus mengembangkan produknya menjadi lebih baik sesuai dengan kebutuhan yang ada guna menarik pembeli baru dan mempertahankan pembeli yang sudah ada. Perusahaan juga harus berfokus terhadap respon pasar agar dapat tetap mempertahankan eksistensi produknya sehingga tetap dilirik oleh konsumen dan dapat melakukan inovasi sesuai kebutuhan pasar sehingga apa yang menjadi dan sedang dibutuhkan oleh konsumen dapat terpenuhi. Perusahaan juga harus mampu untuk memaksimalkan fungsi dari produk-produk yang dijualnya agar konsumen mengerti fungsi keseluruhan dari produk yang tersedia.

\section{IMPLIKASI MANAJERIAL}

Berdasarkan hasil penelitian, maka dapat disampaikan beberapa implikasi manajerial yang dapat diterapkan oleh perusahaan. Terkait dengan persepsi harga, perusahaan diharapkan dapat selalu memberikan pandangan yang sesuai terkait harga yang diberikan agar konsumen tidak kecewa. Untuk kualitas produk, diharapkan perusahaan tetap memberikan kualitas yang baik dalam setiap proses pembuatan produk agar konsumen selalu merasa sesuai ketika menggunakan produk tersebut. Selanjutnya mengenai kepuasan pelanggan diharapkan agar perusahaan selalu memberikan apa yang dibutuhkan oleh konsumen serta agar konsumen selalu merasa diperhatikan dan selalu terpenuhi harapan konsumen mengenai sebuah produk dalam setiap pembelian.

\section{DAFTAR PUSTAKA}

Aryadhe, Pebriana dan Rastini, Ni Made (2016). "Kualitas pelayanan, kualitas produk dan citra merek terhadap niat beli ulang di PT AGUNG TOYOTA Denpasar". E-Jurnal Manajemen Unud, Vol. 5, No.9, 2016:5695-5721. ISSN: 2302-8912.

Awi, Y. L., \& Chaipoopirutana, S. (2014). A Study of Factors Affecting Consumer's Repurchase Intention toward XYZ Restaurant in Myanmar. International Conference on Trends in Economics, Humanities, and Management. 
Chamchuntra, Sutticha dan Fongsuwan Wanno. (2014). Customer Repurchase Intention, Trust and Customer Satisfaction Influecing Outsourced Employees at Kasikorn Bank Public Company Limited (Thailand). International Journal od Arts \& Sciences.7(3):233-242.

Chowdhury, S. R. (2017). Measuring the Relationship Between Product Quality Dimensions \& Repurchase Intention of Smart Phone: A Case study On Chittagong City. International Journal of Scientific \& Engineering Research, Vol 8, ISSN 2229-5518.

Dewi, D. R., Magdalena. M, dan Dhiana. P. (2015). Pengaruh Word of Mouth, Tingkat Pendapatan, dan Kualitas Produk terhadap Keputusan Pembelian yang Berdampak pada Minat Ulang Konsumen. Journal of Management, Vol. 1, No. 1.

Haffman, K. Douglas, Rateson, \& John, E. G. (2011). Services concepts marketing strategies \& cases, South western congage learning, USA.4

Hariyanti, Annisa Dwi. (2011). Analisis Pengaruh Kualitas Produk, Persepsi Harga, dan Kualitas Layanan Terhadap Minat Beli Ulang Produk Perlengkapan Kunci Di Pt. Kenari Djaja Prima Semarang. Jurnal Sains Pemasaran Indonesia Volume X, No. 1, Mei 2011, Halaman $47-87$.

Hellier, Phillip K., et al. (2003). Customer Repurchase Intention: A General Structual Equation Model. Vol.37. Iss 11/12. 1762-1800. Satisfaction, and Brand Resonance to Repurchase Intention.

Huang, Yen, Liu, Chang. (2014). The Relationship Among Brand Equity, Customer Cultural and Creative Industries in Taiwan. The International Journal of Organizational Innovation Vol 6 Num 3 January 2014. Retrieved from htpp://www.ijoionline.org/attachments/article/38/Final_Issue_Vol_6_Num_3_January_2014.pdf\#page= 106.

Hume, M., Dan Mort, G. S. (2010). The consequence of appraisal emotion, service quality, perceived value and customer satisfaction on repurchase intent in the performing arts. Volume 24 • Number 2 • 2010 • 170-182. Emerald Group Publishing Limited [ISSN 0887-6045].

Joseph, O., Onyemachi, Lilian, K.-O., \& Okpara, M. (2012). Analysis of the Determinants of Repurchase Intention of Soap Products of an Agribusiness Firm on Abia State, Nigeria. Journal of Economics and Sustainable Development, 3.

Ketut, Yasa, I. (2018). "The Role of Brand Image Mediating the Effect of Product Quality on Repurchase Intention". Bali. RJOAS, 11(83), November 2018. DOI https://doi.org/10.18551/rjoas.2018-11.20.

Masoom, Khwaja. (2014). The Entrepreneur's Dictionary of Business and Financial Terms. Singapore: Partridge Publishing, 105.

Kotler, P. \& K.L. Keller. (2012). Marketing management. 14th ed. New Jersey: Upper Saddle River.156.

Pupuani, N. W., \& Sulistyawati, E. (2013). Pengaruh Bauran Pemasaran Terhadap Kepuasan Konsumen dan Perilaku Pembelian Ulang (Studi Kasus pada Produk Pasta Gigi Merek Pepsodent di Kota Denpasar). E-Jurnal Management, 2.

Rohwiyati \& Praptiestrini. (2019). "The Effect of Shopee e-Service Quality and Price Perception on Repurchase Intention: Customer Satisfaction as Mediation Variable". Surakata. Indonesian Journal of Contemporary Management Research. Vol 1(1). Journal homepage: http://ibern.org/index.php/ijemr.

Supriono, F. A. (2017). Pengaruh Persepsi Harga dan Kualitas Pelayanan terhadap Minat Pembelian Ulang (Survei pada Konsumen Go-ride di Kota Surabaya). Malang. Jurnal Administrasi Bisnis (JAB). Vol. $50 \quad$ No. 2 september 2017. administrasibisnis.studentjournal.ub.ac.id. 